\title{
$\$$ Research Square \\ Impact of COVID-19 pandemic crisis in Italy: comparison of 2020 with non-pharmaceutical measures and 2021 with pervasive vaccination programs

\author{
Mario Coccia ( $\square$ mario.coccia@cnr.it) \\ National Research Council of Italy
}

\section{Research Article}

Keywords: COVID-19 dynamics, severe acute respiratory syndrome coronavirus-2, Confirmed cases, Vaccination program, Italy, Climate, Seasonality, Health planning

Posted Date: October 25th, 2021

DOI: https://doi.org/10.21203/rs.3.rs-1016797/v1

License: (1) This work is licensed under a Creative Commons Attribution 4.0 International License. Read Full License 


\section{Abstract}

How is the impact of Coronavirus disease 2019 (COVID-19) in Italy in the 2020 (without vaccinations and with non-pharmaceutical interventions) versus 2021 (with a vast roll out of COVID-19 vaccination programs) ? Italy is an interesting case study because was one of first European countries to experience in 2020 higher numbers of COVID-19 related infected individuals and deaths and in 2021 has a high share of people vaccinated against COVID-19.This study answers the question with a comparative analysis of the effects of COVID-19 in 2020 and 2021. Data of confirmed cases, hospitalizations, admissions to ICUs and fatality rate for 176 days are analyzed with the Independent Samples $t$-Test that compares the means of two groups concerning values from April to September 2020 (without vaccinations and with non-pharmaceutical measures) and 2021 (with pharmaceutical interventions based on a vast vaccination program). Results suggest that in 2020 and in 2021 the impact of COVID-19 in society is rather similar, except fatality rate (significant level 1\%). These findings also reveal that the COVID-19 is driven by seasonal and environmental factors that reduce the negative effects in summer period, regardless vaccination campaign. This study can support appropriate and target policy responses of crisis management for countries to face current and likely future pandemics of similar vital agents.

\section{Introduction And Goal Of This Investigation}

The novel Severe Acute Respiratory Syndrome Coronavirus 2 (SARS-CoV-2) is the causative viral agent of the Coronavirus disease 2019 (COVID-19), an infectious illness that is generating health and social issues in manifold countries (Anand et al., 2021; Bontempi and Coccia, 2021; Bontempi et al., 2021; Coccia, 2020, 2020a, 2021; Johns Hopkins Center for System Science and Engineering, 2021). The spread and severity of COVID-19 worldwide has supported the development of new drugs, such as different types of vaccines based on viral vector, protein subunit and nucleic acid (cf., Abbasi, 2020; Coccia, 2021a; Cylus et al., 2021; GAVI, 2021; Heaton, 2020; Jalkanen et al., 2021; Jeyanathan et al., 2020; MAYO Clinic, 2021). A fundamental question in COVID-19 pandemic crisis is whether the reduction of COVID-19 pandemic in 2021 is due to administering of vaccines in population or other factors. Manifold studies show the effects of COVID-19 vaccines on population and health system, emphasizing the effectiveness for the security and well-being in society (Cai et al., 2021; Feng and Li, 2021; Rosenberg et al., 2021). However, inconsistencies and ambiguities in the literature and data of time series suggest the need for additional research. The goal of this investigation is a comparative analysis of the dynamics of COVID-19 pandemic between 2020 and 2021 in Italy, considering infected individuals, hospitalizations, ICUs, and fatality rates. This study analyses the impact of COVID-19 in Italy between AprilSeptember 2020 (without vaccinations and with non-pharmaceutical interventions) and April-September 2021 (with pharmaceutical interventions based on vaccination programs) to explain, whenever possible, the dynamics and impact of COVID-19 pandemic in society. The results are analyzed to clarify the environmental factors determining the dynamics of this pandemic to support socioeconomic and health policies for policymakers.

\section{Theoretical Background}

Because of the rapid spread of COVID-19 worldwide, understanding whether and how the dynamics of COVID19 pandemic in society changes over time is a crucial aspect to clarify driving factors for controlling, with appropriate health planning, the transmission and effects of novel viral agents in society (Aldila et al., 2021; 
Pawelec and McElhaney, 2021). Vaccinations have the potential to keep low basic reproduction number, to relax nonpharmaceutical measures and to support the recovery of socioeconomic systems (cf., Prieto Curiel et al., 2021). Akamatsu et al. (2021) argue that to cope with infectious disease severity that increases considerably, governments have to implement an efficient campaign of vaccinations to reduce infections and mortality in society and avoid the collapse of the healthcare system (cf., Yoshikawa, 2021). Aldila et al. (2021) maintain that higher levels of vaccination can eradicate COVID-19 from the population by achieving, whenever possible, the herd immunity ${ }^{[1]}$ to protect vulnerable individuals (Anderson et al., 2020; de Vlas and Coffeng, 2021, Randolph and Barreiro, 2020; Redwan, 2021). loannidis (2021) suggests a model to assess the benefit of vaccination; in particular, results suggest that if the vaccine efficacy decreases to 0.8 , the benefit gets eroded easily with modest risk compensation. Tran et al. (2021) argue in a case study concerning the states of Rhode Islands and Massachusetts that with vaccination coverage higher than $>28 \%$ and no major changes in nonpharmaceutical measures (social distancing, masking, gathering size, hygiene guidelines, etc.) and virus transmissibility from January to July, a combination of vaccination and population immunity may lead to low or near-zero transmission levels by the second quarter of 2021.

However, other climatological, environmental, demographic, and geographical factors of the total environment can influence the spread of COVID-19 in society (Bashir et al., 2020; Rosario et al., 2020; Sahin, 2020; Sarmadi et al., 2020). Zhong et al. (2018) argue that static meteorological conditions may explain the increase of bacterial communities in the presence of air pollution. Coccia (2020) reveals that, among Italian provincial capitals, the number of infected people was higher in cities having high air pollution, cities located in hinterland zones (i.e., away from the coast), cities having a low wind speed and cities with a lower temperature (cf., Coccia 2020c; 2021b, 2021h). Rosario et al. (2020) also reveal that high wind speed improves the circulation of air and increases the exposure of the novel coronavirus to the solar radiation effects, a factor having a negative correlation in the environmental diffusion of COVID-19. Abraham et al. (2021) suggest that the vital role of climatic variables and seasonality in all kinds of epidemics and pandemics, included COVID-19. Zoran et al., (2021), analyzing COVID-19 waves in Madrid, maintain that air temperature, planetary boundary layer height, and ground level ozone have a significant negative relationship with daily new COVID-19 confirmed cases and deaths. Danon et al. (2021) show that seasonal changes in transmission rate can affect the timing and size of the epidemic potential of COVID-19; in particular, seasonal changes in transmission could shift the timing of the peak into winter, with important implications for healthcare capacity planning.

In this context, a key problem in current COVID-19 pandemic crisis is to examine the evolution of COVID-19 into the same spatial area and period in 2020 and 2021 to explain variations or similarities of the effects in society. This study confronts this problem here by developing a comparative analysis between April-September 2020 (without vaccinations and with non-pharmaceutical interventions) and April-September 2021 (with vaccination programs) in Italy, which was the first European country to experience a rapid increase in confirmed cases and deaths of COVID-19 in 2020 and in 2021 is one of the countries with a widespread plan of vaccination.

The study here can provide critical results to clarify the dynamics of COVID-19 pandemic, environmental behavior and effects of the novel Coronavirus in society. Lessons learned from this study could be of benefit to countries to design effective strategies of healthcare capacity planning to apply in specific period to cope with and/or to prevent future waves of COVID-19 and/or epidemics/pandemics of similar infectious diseases. This study is part of a large body of research directed to explain drivers of transmission dynamics of COVID-19 and 
design effective COVID-19 pandemic responses of crisis management (Coccia, 2020, 2020a, 2020b, 2020c, 2021, 2021c, 2021d, 2021e, 2021h, 2022).

[1] Herd immunity indicates that only a share of a population needs to be immune and as a consequence no longer susceptible (by overcoming natural infection or through vaccination) to a viral agent for epidemic control and to stop large outbreaks (Fontanet and Cauchemez, 2020; Rosen et al., 2021).

\section{Materials And Methods}

\subsection{Research questions}

How is the dynamics of the COVID-19 pandemic in summer season of 2020 (without vaccines) and 2021 (with vaccinations)?

Does the behavior of COVID-19 change or not between 2020 (without vaccines) and 2021 (with vaccinations)?

The goal of this study is a comparative analysis of the effects of COVID-19 pandemic between 2020 (without vaccinations and with non-pharmaceutical interventions) and 2021 (with vaccination programs) in Italy to assess differences or similarities in society (cf., Coccia, 2018).

\subsection{Research setting}

The research setting here is a case study of Italy, the first European country to experience a rapid increase of COVID-19 related infected individuals and deaths in 2020 (Coccia, 2020, 2021). Moreover, Italy on 27 September 2021 is one of the countries with widespread plan of vaccination having a share of people fully and only partly vaccinated against COVID-19 equal to about 74\% (Lab24, 2021; Mathieu et al., 2021; Our World in Data, 2021).

\subsection{Period, sample and source}

Data of the period from $1^{\text {st }}$ April to $23^{\text {rd }}$ September 2020 are compared to the same period in 2021 in Italy, using daily information based on $N=176$ days in 2020 and $N=176$ days in 2021 for a total of $N=352$ cases for different variables. Source of epidemiological data under study is The Ministry of Health in Italy (Ministero della Salute, 2020).

\subsection{Measures}

The measures for statistical analyses are:

- Number of daily COVID-19 infected individuals is measured with confirmed cases of COVID-19 in population per day.

- Number of daily COVID-19 swab tests verifies the positivity to the novel coronavirus (confirmed case) by analyzing specimen of people (LabCorp, 2020). 
- Daily hospitalized people are the total hospitalized patients with different COVID-19 symptoms and patients in ICUs.

- Daily admissions to Intensive Care Units (ICUs) are the number of patients in ICUs for COVID-19.

- Number of daily COVID-19 deaths is measured with total deaths per day in society

- Daily Fatality rate $=$ ratio of deaths at $(t) /$ confirmed cases at $(t-14)$. The time lag of about 14 days from initial symptoms to deaths is based on empirical evidence of some studies (Zhang et al., 2020).

\subsection{Data analysis procedure}

Firstly, the study calculates the daily contagiousness coefficient of COVID-19 in the period under study of 2020 and 2021, given by:

\section{Contagiousness coefficient of COVID -19 at $t(\mathrm{CCV})=\frac{\text { Confirmed cases at } t}{\text { swab tests at } t}$}

This coefficient is used to normalize hospitalization and admissions to ICUs. Moreover, to eliminate from original time series $y_{\mathrm{t}}$ weekly seasonal variation, it is applied the method of moving averages $(\mathrm{MM})$ considering the sub-period of length $r=7$ days (a week), using the following formula for MM7:

$$
y_{t}^{\prime}=\frac{y_{t-3}+y_{t-2}+y_{t-1}^{m}+y_{t}+y_{t+1}+y_{t+2}^{m}+y_{t+3}^{m}}{r=7 \text { days }}
$$

New time series adjusted with averaging process is given by $y_{t}^{*}=\sum_{t}^{s} y_{t}^{\prime}$ that tends to eliminate period to period weakly fluctuations and produces a much smoother series than original observations. Data of daily hospitalization of people and admissions to ICUs are normalized as follows:

$$
\text { Daily hospitalization of people normalized }=\frac{\text { daily hospitalization of people }(t)}{M M 7 \text { Contagiousness coefficient of COVID }-19(t-5)}
$$

$$
\text { Daily admission ICUs normalized }=\frac{\text { daily admission ICUs }(\mathrm{t})}{M M 7 \text { Contagiousness coefficient of COVID }-19(\mathrm{t}-5)}
$$

The time lag of about 5 days to normalize these variables is based on an average period from diagnosis (initial symptoms and positivity to swab test) to the hospitalization and recovery in ICUs of COVID-19 patients as explained by specific studies (Faes et al., 2020).

The sample of $N=352$ cases is divided in two sub-samples having similar temporal, healthcare and societal conditions for a structural comparative analysis: 
- group 1: data from 1st April to $23^{\text {rd }}$ September 2020, $N=176$

- group 2: data from 1 st April to $23^{\text {rd }}$ September 2021, $N=176$

Secondly, data are analyzed with descriptive statistics given by arithmetic mean (M) and Std. error of mean (SEM) for a comparative analysis between two groups just mentioned.

Thirdly, follow-up investigation is the Independent Samples t-Test that compares the means of two independent groups to determine whether there is statistical evidence that the associated population means are significantly different. The assumption of homogeneity of variance in the Independent Samples $t$ Test - i.e., both groups have the same variance -- is verified with Levene's Test based on following statistical hypotheses:

$H_{0}: \sigma_{1}^{2}-\sigma_{2}^{2}=0$ (population variances of group 1 and 2 are equal)

$H_{1}: \sigma_{1}^{2}-\sigma_{2}^{2} \neq 0$ (population variances of group 1 and 2 are not equal)

The rejection of the null hypothesis in Levene's Test suggests that variances of the two groups are not equal: i.e., the assumption of homogeneity of variances is violated. If Levene's test indicates that the variances are equal between the two groups (i.e., $p$-value large), equal variances are assumed. If Levene's test indicates that the variances are not equal between the two groups (i.e., $p$-value small), the assumption is that equal variances are not assumed.

After that, null hypothesis $\left(H_{0}^{\prime}\right)$ and alternative hypothesis $\left(H_{1}^{\prime}\right)$ of the Independent Samples $t$-Test are:

$H_{0}^{\prime}: \mu_{1}=\mu_{2}$, the two-population means are equal in 2020 and 2021

$H_{1}^{\prime}: \mu_{1} \neq \mu_{2}$, the two-population means are not equal in 2020 and 2021

Finally, trends of variables under study are analyzed and visualized for a comparative analysis of the impact of COVID-10 pandemic in Italy between 2020 (without vaccinations and with non-pharmaceutical interventions) and 2021 (with pharmaceutical interventions based on vast roll out of COVID-19 vaccination). In particular, this study also applies a simple regression analysis in which response variables measuring the impact of the COVID-19 on health of people are a linear function of time. The specification of linear relationship is given by a model using the time series $y^{*}$ in 2020 and 2021:

$\log y_{t}^{*}=\mathrm{a}+\mathrm{b} t+u$

$y^{*}{ }_{t}=\quad$ measures of the impact of COVID-19 pandemic in society using MM7 of time series (Confirmed cases/swab tests, Hospitalization an ICUs)

$t=\quad$ time given by 2020 and 2021 period, as explained before

$u=\quad$ error term

Ordinary Least Squares (OLS) method is applied for estimating the unknown parameters of linear model [1]. 
Statistical analyses are performed with the Statistics Software SPSSâ version 26.

\section{Results}

Table 1 shows that confirmed cases in 2020 is about $2.1 \%$, whereas in 2021 is $2.5 \%$. Number of hospitalizations, ICUs in 2020 has a slightly higher level, whereas fatality rate is lower in 2021 compared to 2021 , likely because of a higher number of swab tests in 2021 that have detected more confirmed cases that increase the denominator of the ratio of fatality reducing the total value.

Table 1. Descriptive statistics

April-September $2020 \quad$ April-September 2021

\begin{tabular}{|c|c|c|c|c|}
\hline Description of variables & $M$ & Std. Error Mean & $M$ & Std. Error Mean \\
\hline & 0.021 & 0.002 & 0.0254 & 0.0012 \\
\hline - Hospitalizations normalized & 556.720 & 94.706 & 406.0100 & 46.8410 \\
\hline - ICUs normalized & 58.850 & 11.076 & 48.0400 & 5.4400 \\
\hline - Fatality rates & 0.073 & 0.003 & 0.0146 & 0.0004 \\
\hline
\end{tabular}

Note: $\mathrm{M}=$ arithmetic mean, $N=176$ days in 2020 and 176 in 2021

Table 2 shows the Independent Samples $t$ Test, as follow-up inspection, to assess the significance of the difference of arithmetic mean between groups of 2020 and 2021 under study. The $p$-value of Levene's test is significant, and we have to reject the null hypothesis of Levene's test and conclude that the variance in the groups under study is significantly different (i.e., equal variances are not assumed). Table 2 also shows $t$-test for Equality of Means that provides the results for the actual Independent Samples $t$ Test.

Since $p$-value $\geq 0.5$ is higher than fixed significance level $a=0.01$, we can accept the null hypothesis, and conclude that the mean of confirmed cases, hospitalizations of people, and ICUs in 2020 and 2021 is significantly equal: there is not a significant difference in arithmetic mean between 2020 and 2021. Instead, for fatality rates, since $p$-value $<0.001$ is less than chosen significance level $a=0.01$, we can reject the null hypothesis, and conclude that the mean in 2021 and 2021 is significantly different, likely for reasons mentioned for table 1 .

Table 2. Independent Samples Test 


\begin{tabular}{|c|c|c|c|c|c|c|c|c|}
\hline & & \multicolumn{2}{|c|}{$\begin{array}{l}\text { Levene's Test for } \\
\text { equality of } \\
\text { variances }\end{array}$} & \multicolumn{5}{|c|}{$t$-test for equality of Means } \\
\hline & & F & Sig. & $t$ & df & $\begin{array}{c}\text { Sig. } \\
\text { (2-tailed) }\end{array}$ & $\begin{array}{c}\text { Mean } \\
\text { Difference }\end{array}$ & $\begin{array}{l}\text { Std. Error } \\
\text { Difference }\end{array}$ \\
\hline \multirow[t]{2}{*}{$\begin{array}{r}\text { Confirmed cases } \\
2020 \text { vs. } 2021\end{array}$} & $\bullet$ Equal variances assumed & 11.722 & 0.001 & -1.631 & 350 & 0.104 & -0.004 & 0.002 \\
\hline & $\begin{array}{l}\bullet \text { Equal variances not } \\
\text { assumed }\end{array}$ & & & -1.631 & 276.877 & 0.104 & -0.004 & 0.002 \\
\hline \multirow[t]{2}{*}{$\begin{array}{r}\text { Hospitalizations } \\
2020 \text { vs. } 2021\end{array}$} & •Equal variances assumed & 18.541 & 0 & 1.426 & 350 & 0.155 & 150.716 & 105.657 \\
\hline & $\begin{array}{l}\text {-Equal variances not } \\
\text { assumed }\end{array}$ & & & 1.426 & 255.784 & 0.155 & 150.716 & 105.657 \\
\hline \multirow[t]{2}{*}{$\begin{array}{r}\text { ICUs } \\
2020 \text { vs. } 2021\end{array}$} & -Equal variances assumed & 12.436 & 0 & 0.876 & 350 & 0.382 & 10.813 & 12.340 \\
\hline & $\begin{array}{l}\bullet \text { Equal variances not } \\
\text { assumed }\end{array}$ & & & 0.876 & 254.772 & 0.382 & 10.813 & 12.340 \\
\hline \multirow[t]{2}{*}{$\begin{array}{r}\text { Fatality rates } \\
2020 \text { vs. } 2021\end{array}$} & -Equal variances assumed & 446.728 & 0 & 17.812 & 350 & 0 & 0.058 & 0.003 \\
\hline & $\begin{array}{l}\text { •Equal variances not } \\
\text { assumed }\end{array}$ & & & 17.812 & 180.875 & 0 & 0.058 & 0.003 \\
\hline
\end{tabular}

Table 3 and figures 1-4 confirm, ictu oculi, previous results. Simple regression analysis in table 3 shows, in average, a higher reduction in 2020 than year 2021 of the coefficients of regression of response variables under study $(p$-value $=.001)$.

The coefficient $\mathrm{R}^{2}$ of regression models indicates that from $24 \%$ to $70 \%$ of the variation in variables of the COVID-19 can be attributed (linearly) to temporal variable. F-test is significant with $p$-value $<.001$.

Conclusion of statistical analyses here is that the dynamics of pandemics in 2020 and 2021 is rather similar, regardless the plan of vaccination implemented by Italy. Results seem to suggest that the negative effects of COVID-19 in Italy are higher in 2021, though vaccination campaign, than 2020 (without vaccination), likely because of delta variant of SARS-CoV-2 that has a higher transmission dynamics (GAVI, 2021).

Table 3. Estimated relationships based on linear model of regression 


\begin{tabular}{|c|c|c|c|c|}
\hline & \multicolumn{2}{|c|}{ Confirmed cases } & \multicolumn{2}{|c|}{ Hospitalizations } \\
\hline & 2020 & 2021 & 2020 & 2021 \\
\hline Constant $\alpha$ & $0.050 * \star \star$ & $0.066 * \star \star *$ & 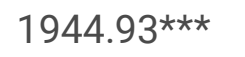 & $2768.46 * \star \star$ \\
\hline Coefficient $\beta$ & $-0.00032^{\star \star \star}$ & $-0.00015^{\star \star \star}$ & $-15.69 * \star \star$ & $-8.93 * \star \star$ \\
\hline Stand. Coeff. $\beta$ & -0.58 & -0.49 & -0.64 & -0.73 \\
\hline $\mathrm{R}^{2}$ & 0.334 & 0.143 & 0.41 & 0.54 \\
\hline \multirow[t]{3}{*}{ F-test } & $87.25^{\star \star \star}$ & $55.79 * \star \star$ & 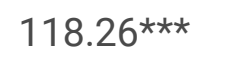 & $201.25^{\star \star \star}$ \\
\hline & \multicolumn{2}{|l|}{ ICUs } & \multicolumn{2}{|l|}{ Fatality rates } \\
\hline & 2020 & 2021 & 2020 & 2021 \\
\hline Constant $\alpha$ & $210.48^{\star \star \star}$ & $327.21 * \star \star$ & $0.14^{\star \star \star}$ & $0.04 * \star \star$ \\
\hline Coefficient $\beta$ & 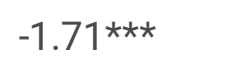 & 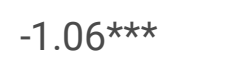 & $-0.001^{\star \star \star}$ & $-0.00009 * * *$ \\
\hline Stand. Coeff. $\beta$ & -0.594 & -0.745 & -.84 & -.78 \\
\hline $\mathrm{R}^{2}$ & 0.35 & 0.55 & 0.71 & 0.60 \\
\hline F-test & $94.90 * \star \star$ & $217.30 * \star \star *$ & $416.01 \star \star \star *$ & $264.00 * \star \star$ \\
\hline
\end{tabular}

Notes: $\quad$ Explanatory variable: Case sequence (time)

Response variables: Hospitalizations normalized, confirmed cases normalized , ICUs normalized, Fatality rates Significance: ${ }^{* * *} p$-value $<0.001,{ }^{*} p-$ value $<0.5$

\section{Phenomena Expalined Of The Similar Dynamics Of Covid-19 In 2020 And 2021}

The results of this study show a comparative analysis of the effects of COVID-19 in 2020 (with nonpharmaceutical interventions) versus 2021 (with vast vaccination programs) in the same socioeconomic system, given by Italy. Results reveal similar dynamics of COVID-19, regardless vaccinations. These results may be interpreted through the lens of theories that explain the critical role of climatic variables and seasonality in all types of epidemics and pandemics based on airborne diseases (Abraham et al., 2021; Dbouk and Drikakis, 2020; lanevski et al., 2019). Manifold studies suggest that the important role of climate on the spread of influenza viruses, such as SARS-CoV-2 (Takagi et al., 2020; Şahin, 2020). In general, meteorological factors (e.g., temperature and humidity) play a well-established role in the seasonal transmission of respiratory viruses and influenza in temperate climates (Chan et al., 2011; Hoogeveen and Hoogeveen, 2021; Roussel et al., 2016). Studies report that the transmission of COVID-19 can be influenced by the variation of environmental factors associated with seasonality (Christophi et al., 2021; Maharaj et al., 2021). In fact, summer seasonality can reduce the spread of the airborne disease of novel coronavirus over time and space and constrain the negative effects in society in the presence of specific conditions of the total environment; in particular, while a higher absolute humidity can support viral transmission (Islam et al., 2021), high solar radiation and high wind speed can mitigate the spread of COVID-19 in society (Coccia, 2021, 2021a; Rosario et al., 2020). Scholars suggest 
that the effects of climate on the influenza epidemic are associated with seasonal fluctuations connected with latitude in the North and South Hemisphere (lanevski et al., 2019; Shaman and Galanti, 2020). Especially, scholars analyze the sensitivity of COVID-19 to meteorological factors to explain how changes in the weather and seasonality may constrain COVID-19 transmission (Kerr et al., 2021). Recent studies point out the strong seasonal factor of COVID-19 (Audi et al., 2020; Moriyama et al., 2020). The study by Liu et al. (2021, p.1ff) shows that the cold season in the Southern Hemisphere countries caused a $59.71 \pm 8.72 \%$ increase of total infections, whereas the warm season in the Northern Hemisphere countries contributed to a $46.38 \pm 29.10 \%$ reduction.

These results propose that COVID-19 seasonality is more pronounced at higher latitudes, in the presence of larger seasonal amplitudes in environment. Other studies have focused on temperature or humidity effects that might slow down transmission of the novel coronavirus (Karapiperis et al., 2021; Rosario et al., 2020; Runkle et al., 2020). Byun et al. (2021) show that that manifold studies suggest an inverse relation between temperature and humidity, and global transmission of SARS-CoV-2. As matter of fact, COVID-19 tends to be temperaturesensitive and, therefore driven by a seasonal viral agent (cf., Engelbrecht and Scholes, 2021). In this context, Karapiperis et al. (2021) demonstrated that UV radiation is strongly associated with incidence rates, rather than mobility, suggesting that UV radiation is a seasonality indicator for COVID-19, irrespective of the initial conditions of the epidemic (cf., Kumar et al., 2021). Many infectious diseases, such as endemic human coronaviruses, can be a seasonally recurrent infectious diseases that vary over time and space (Kronfeld-Schor et al., 2021). Although, a vital relationship between weather seasonality, airborne virus transmission, environmental factors, air pollution and pandemic disease exists over time (Coccia, 2020), Dbouk and Drikakis (2020) maintain that many epidemiologic models do not consider the effects of climate conditions on the transmission dynamics of viruses about airborne diseases. Additionally, Dbouk and Drikakis (2021), applying fluid dynamics simulations, show that weather seasonality can induce two outbreaks of the COVID-19 pandemic worldwide. These two pandemic outbreaks per year are inevitable because they are directly associated with weather seasonality based on temperature, relative humidity, and wind speed of geographical regions.

Hence, the empirical evidence seems to suggest that the novel coronavirus pandemic has a full seasonal cycle, showing a negative correlation of the rate of diffusion with humidity and temperature (Karapiperis et al., 2021): i.e., the SARS-CoV2 transmissibility seems to naturally decrease in summer seasons, regardless vaccinations.

Therefore, many studies-analyzing the role of climate and seasonality of pandemic diseases-have proposed an extension of the family of epidemiologic models with the introduction of parameters associated with seasonality transmission of SARS-CoV-2 and other socioeconomic factors (Batabyal, 2021; Bontempi and Coccia, 2021; Bontempi et al., 2021; Coccia, 2020a).

The proposed explanation here of similar trends of the dynamics of COVID-19 pandemic in 2020 and 2021 based on the factor of seasonality and other environmental factors in the spread of the novel coronavirus is a critical aspect to design and implement appropriate public health interventions and timing of health planning of vaccination and other non-pharmaceutical interventions in society.

\section{Concluding Observations And Limitations}

Page $10 / 23$ 
This study reveals,-with a comparative analysis between the period April-September 2020 (without vaccinations but applying non-pharmaceutical interventions) and April-September 2021 (with a pervasive roll out of COVID19 vaccinations) in Italy-, that average confirmed cases, hospitalizations of people, and admissions to ICUs is significantly equal, corroborating the seasonal behavior in the total environment of the COVID-19, which decreases in summer season regardless vaccinations[2].

This finding has a critical aspect to clarify transmission dynamics and support appropriate interventions of health policy to cope with outbreaks of current and future infectious diseases. In fact, these results can support the implementation of best practices of public health and policy of new technology[3], considering seasonal factor in the Northern and Southern Hemispheres, in which the COVID-19 and similar infectious diseases unfold mainly over winter-fall period (cf., Coccia, 2021f; Gozzi et al., 2021; Yoshikawa, 2021).

Danon et al. (2021) show that seasonal changes in transmission rate can affect the timing and size of the COVID-19 pandemic, shifting the peak into winter, with important implications for planning the healthcare capacity and vaccinations to cope with infectious diseases[4]. As a matter of fact, Smit et al. (2021) argue that climatic factors would reduce the viral transmission rate in boreal summer and the COVID-19 peak would coincide with the peak of the influenza season, increasing the burden on health systems (cf., Kronfeld-Schor et al., 2021). However, seasonality alone can be a main driver in transmission dynamics of COVID-19 but cannot be a sufficient factor to curb the novel coronavirus transmission that requires multidisciplinary approaches and timely intervention policies of short and long run, a scaled-up health care capacity in the winter seasons, rather than summer period.

Overall, then, this statistical analysis here suggests that the reduction of the dynamics of COVID-seems to be associated with seasonality of the novel coronavirus that reduces the effects in the presence of favorable conditions of summer season that constrain the spread of the airborne disease in society. These conclusions are, of course, tentative. Although this study has provided some interesting, albeit preliminary results, it has several limitations. First, COVID-19 pandemic is still progressing, so data are continually changing over time and space. Second, structure of population and characteristics of patients (e.g., ethnicity, age, sex, and comorbidities) may vary between regions affecting results. Third, there are multiple confounding factors that could have an important role in the spread of COVID-19 pandemic to be further investigated (e.g., institutional aspects, culture, investments in hospital sector, in prevention, in medical personnel, etc.). Finally, the statistical analyses and estimated relationships in this study focus on data in specific period (which were the recent information available in the database) and country having as Mediterranean climate (Italy). Thus, generalizing the results of this research should be done with caution.

To conclude, future research should consider more recent data, when available, and when possible, should examine new time series of variables to provide more dynamic relations of the phenomena under study over time and space. Despite these limitations, the results presented here clearly illustrate the need for more detailed examinations of the relationship between dynamics of COVID-19 and climate factors to better understand transmission dynamics of COVID-19 over time for appropriate policy responses of crisis management at country level.

[2] The reduction in summer of COVID-19 cases is also due to a lower level of pollution and better climate factors (cf., Coccia, 2014, 2020b, 2020c) 
[3] For vital role of technology diffusion and evolution see: Calabrese et al., 2005; Coccia, 2012, Coccia, 2016, 2016a; 2017a, 2017c, 2017d, 2019a, 2019b, 2020d, 2020e; Coccia and Finardi, 2012, 2013; Coccia and Watts, 2020, Coccia and Wang, 2015, 2016.

[4] Planning the healthcare capacity of nations depends also on other factors (cf., Coccia, 2005, 2005a, 2005b; 2006, 2008, 2009, 2010, 2015, 2016b, 2017, 2017b, 2018a, 2018b, 2018c, 2018d, 2019, 2019c, 2021g, Coccia and Bellitto, 2018; Coccia and Benati, 2018; Coccia and Cadario, 2014; Coccia and Rolfo, 2010.

\section{Declarations}

\section{Declaration of competing interest}

The author declares that he is the sole author of this manuscript, and he has no known competing financial interests or personal relationships that could have appeared to influence the work reported in this paper.

This study has no funders.

\section{References}

Abbasi J. 2020. COVID-19 and mRNA Vaccines-First Large Test for a New Approach. JAMA, 324(12), 11251127. https://doi.org/10.1001/jama.2020.16866

Abraham, J., Turville, C., Dowling, K., Florentine, S. 2021. Does climate play any role in covid-19 spreading?-an Australian perspective, International Journal of Environmental Research and Public Health 18(17),9086

Akamatsu, T., Nagae, T., Osawa, M., Satsukawa, K., Sakai, T., Mizutani, D. 2021. Model-based analysis on social acceptability and feasibility of a focused protection strategy against the COVID-19 pandemic. Scientific reports, 11(1), 2003. https://doi.org/10.1038/s41598-021-81630-9

Aldila, D., Samiadji, B.M., Simorangkir, G.M., Khosnaw, S.H.A., Shahzad, M.2021. Impact of early detection and vaccination strategy in COVID-19 eradication program in Jakarta, Indonesia, BMC Research Notes, 14(1),132

Anand, U., Cabreros, C., Mal, J., Ballesteros, F., Jr, Sillanpää, M., Tripathi, V., \& Bontempi, E. 2021. Novel coronavirus disease 2019 (COVID-19) pandemic: From transmission to control with an interdisciplinary vision. Environmental research, 197, 111126. https://doi.org/10.1016/j.envres.2021.111126

Anderson, R. M., Vegvari, C., Truscott, J., Collyer, B. S. 2020. Challenges in creating herd immunity to SARS-CoV2 infection by mass vaccination. Lancet (London, England), 396(10263), 1614-1616.

https://doi.org/10.1016/S0140-6736(20)32318-7

Audi, A.; Alibrahim, M.; Kaddoura, M.; Hijazi, G.; Yassine, H.M.; Zaraket, H. Seasonality of Respiratory Viral Infections: Will

Bashir M.F., Ma, B., Bilal, Komal, B., Bashir, M.A., Tan, D., Bashir, M. 2020. Correlation between climate indicators and COVID-19 pandemic in New York, USA, Science of the Total Environment, 728, art. no. 138835. 
Batabyal, S. 2021. COVID-19: Perturbation dynamics resulting chaos to stable with seasonality transmission, Chaos, Solitons and Fractals 145,110772

Bontempi E., Coccia M., 2021. International trade as critical parameter of COVID-19 spread that outclasses demographic, economic, environmental, and pollution factors, Environmental Research, vol. 201, Article number 111514, PII S0013-9351(21)00808-2, https://doi.org/10.1016/j.envres.2021.111514, ISSN 0013-9351

Bontempi E., Coccia M., Vergalli S., Zanoletti A. 2021. Can commercial trade represent the main indicator of the COVID-19 diffusion due to human-to-human interactions? A comparative analysis between Italy, France, and Spain, Environmental Research, vol. 201, Article number 111529, PII S0013-9351(21)00823-9, https://doi.org/10.1016/j.envres.2021.111529, ISSN 0013-9351

Byun WS, Heo SW, Jo G, Kim JW, Kim S, Lee S, Park HE, Baek JH. 2021. Is coronavirus disease (COVID-19) seasonal? A critical analysis of empirical and epidemiological studies at global and local scales. Environ Res. 2021 May;196:110972. Doi: 10.1016/j.envres.2021.110972.

Cai C., Peng Y., Shen, E., (... Zeng S., Shen H. 2021. A comprehensive analysis of the efficacy and safety of COVID-19 vaccines, Molecular Therapy 29(9), pp. 2794-2805

Calabrese G., Coccia M., Rolfo S. 2005. Strategy and market management of new product development: evidence from Italian SMEs. International Journal of Product Development, vol. 2, n. 1-2, pp. 170-189. https://doi.org/10.1504/IJPD.2005.006675

Chan, K.H., Peiris, J.S.M., Lam, S.Y., Poon, L.L.M., Yuen, K.Y., Seto, W.H. 2011. The effects of temperature and relative humidity on the viability of the SARS coronavirus, (2011) Advances in Virology, 2011, art. no. 734690.

Christophi, C.A., Sotos-Prieto, M., Lan, F.-Y., (... Rodriguez-Artalejo, F., Kales, S.N. 2021. Ambient temperature and subsequent COVID-19 mortality in the OECD countries and individual United States, Scientific Reports $11(1), 8710$

Coccia M. 2005. A taxonomy of public research bodies: a systemic approach, Prometheus -The journal of issues in technological change. Innovation. Information economics, communications and science policy, vol. 23, n. 1, pp. 63-82. https://doi.org/10.1080/0810902042000331322

Coccia M. 2005a. Metrics to measure the technology transfer absorption: analysis of the relationship between institutes and adopters in northern Italy. International Journal of Technology Transfer and Commercialization, vol. 4, n. 4, pp. 462-486. https://doi.org/10.1504/IJTTC.2005.006699

Coccia M. 2005b. Countrymetrics: valutazione della performance economica e tecnologica dei paesi e posizionamento dell'Italia, Rivista Internazionale di Scienze Sociali, vol. CXIII, n. 3, pp. 377-412. Stable URL: http://www.jstor.org/stable/41624216.

Coccia M. 2006. Analysis and classification of public research institutes, World Review of Science, Technology and Sustainable Development, vol. 3, n. 1, pp.1-16. https://doi.org/10.1504/WRSTSD.2006.008759 
Coccia M. 2008. Measuring scientific performance of public research units for strategic change. Journal of Informetrics, vol. 2, n. 3, pp. 183-194. https://doi.org/10.1016/j.joi.2008.04.001

Coccia M. 2009. Research performance and bureaucracy within public research labs, Scientometrics, vol. 79, n. 1, pp. 93-107. https://doi.org/10.1007/s11192-009-0406-2

Coccia M. 2010. Spatial patterns of technology transfer and measurement of its friction in the geo-economic space. International Journal of Technology Transfer and Commercialisation, vol. 9, n. 3, pp. 255-267. https://doi.org/10.1504/IJTTC.2010.030214

Coccia M. 2012. Converging genetics, genomics and nanotechnologies for groundbreaking pathways in biomedicine and nanomedicine. Int. J. Healthcare Technology and Management, vol. 13, n. 4, pp. 184-197. https://doi.org/10.1504/IJHTM.2012.050616

Coccia M. 2014. Steel market and global trends of leading geo-economic players. International Journal of trade and global markets, vol. 7, n.1, pp. 36-52, http://dx.doi.org/10.1504/IJTGM.2014.058714

Coccia M. 2015. Spatial relation between geo-climate zones and technological outputs to explain the evolution of technology. Int. J. Transitions and Innovation Systems, vol. 4, nos. 1-2, pp. 5-21, http://dx.doi.org/10.1504/IJTIS.2015.074642.

Coccia M. 2016. Problem-driven innovations in drug discovery: co-evolution of the patterns of radical innovation with the evolution of problems, Health Policy and Technology, vol. 5, n. 2, pp. 143-155. https://doi.org/10.1016/j.hlpt.2016.02.003

Coccia M. 2016a. Radical innovations as drivers of breakthroughs: characteristics and properties of the management of technology leading to superior organizational performance in the discovery process of R\&D labs, Technology Analysis \& Strategic Management, vol. 28, n. 4, pp. 381-395, https://doi.org/10.1080/09537325.2015.1095287

Coccia M. 2016b. The relation between price setting in markets and asymmetries of systems of measurement of goods, The Journal of Economic Asymmetries, vol. 14, part B, November, pp. 168-178, https://doi.org/10.1016/j.jeca.2016.06.001

Coccia M. 2017. Varieties of capitalism's theory of innovation and a conceptual integration with leadershiporiented executives: the relation between typologies of executive, technological and socioeconomic performances. Int. J. Public Sector Performance Management, Vol. 3, No. 2, pp. 148-168. https://doi.org/10.1504/IJPSPM.2017.084672

Coccia M. 2017a. Disruptive firms and industrial change, Journal of Economic and Social Thought, vol. 4, n. 4, pp. 437-450, http://dx.doi.org/10.1453/jest.v4i4.1511

Coccia M. 2017b. New directions in measurement of economic growth, development and under development, Journal of Economics and Political Economy, vol. 4, n. 4, pp. 382-395, http://dx.doi.org/10.1453/jepe.v4i4.1533 
Coccia M. 2017c. Sources of disruptive technologies for industrial change. L'industria -rivista di economia e politica industriale, vol. 38, n. 1, pp. 97-120, DOI: 10.1430/87140

Coccia M. 2017d. Sources of technological innovation: Radical and incremental innovation problem-driven to support competitive advantage of firms. Technology Analysis \& Strategic Management, vol. 29, n. 9, pp. 10481061, https://doi.org/10.1080/09537325.2016.1268682

Coccia M. 2018. An introduction to the methods of inquiry in social sciences, Journal of Social and Administrative Sciences, vol. 5, n. 2, pp. 116-126, http://dx.doi.org/10.1453/jsas.v5i2.1651

Coccia M. 2018a. An introduction to the theories of institutional change, Journal of Economics Library, vol. 5, n. 4, pp. 337-344, http://dx.doi.org/10.1453/jel.v5i4.1788

Coccia M. 2018b. Motivations of scientific research in society. Journal of Social and Administrative Sciences, vol. 5, n. 3, pp. 196-216. http://dx.doi.org/10.1453/jsas.v5i3.1680

Coccia M. 2018c. General properties of the evolution of research fields: a scientometric study of human microbiome, evolutionary robotics and astrobiology, Scientometrics, vol. 117, n. 2, pp. 1265-1283, https://doi.org/10.1007/s11192-018-2902-8

Coccia M. 2018d. The origins of the economics of Innovation, Journal of Economic and Social Thought, vol. 5, n. 1, pp. 9-28. http://dx.doi.org/10.1453/jest.v5i1.1574

Coccia M. 2019. Why do nations produce science advances and new technology? Technology in society, vol. 59, November, 101124, pp. 1-9, https://doi.org/10.1016/j.techsoc.2019.03.007

Coccia M. 2019a. The theory of technological parasitism for the measurement of the evolution of technology and technological forecasting, Technological Forecasting and Social Change, vol. 141, pp. 289-304, https://doi.org/10.1016/j.techfore.2018.12.012

Coccia M. 2019b. A Theory of classification and evolution of technologies within a Generalized Darwinism, Technology Analysis \& Strategic Management, vol. 31, n. 5, pp. 517-531, http://dx.doi.org/10.1080/09537325.2018.1523385

Coccia M. 2019c. Theories of Development. A. Farazmand (ed.), Global Encyclopedia of Public Administration, Public Policy, and Governance, Springer Nature, https://doi.org/10.1007/978-3-319-31816-5_939-1

Coccia M. 2020. Factors determining the diffusion of COVID-19 and suggested strategy to prevent future accelerated viral infectivity similar to COVID. Science of The Total Environment 729, 138474, https://doi.org/10.1016/j.scitotenv.2020.138474.

Coccia M. 2020a. An index to quantify environmental risk of exposure to future epidemics of the COVID-19 and similar viral agents: Theory and Practice. Environmental Research, Article number 110155, https://doi.org/10.1016/j.envres.2020.110155

Coccia M. 2020b. How do environmental, demographic, and geographical factors influence the spread of COVID-19. Journal of Social and Administrative Sciences, vol. 7, no. 3, pp. 169-209. 
http://dx.doi.org/10.1453/jsas.v7i3.2018

Coccia M. 2020c. How (un)sustainable Environments are Related to the Diffusion of COVID-19: The Relation between Coronavirus Disease 2019, Air Pollution, Wind Resource and Energy. Sustainability 2020, 12, 9709; doi:10.3390/su12229709

Coccia M. 2020d. Destructive Technologies for Industrial and Corporate Change. In: Farazmand A. (eds), Global Encyclopedia of Public Administration, Public Policy, and Governance. Springer, Cham, https://doi.org/10.1007/978-3-319-31816-5_3972-1

Coccia M. 2020e. Deep learning technology for improving cancer care in society: new directions in cancer imaging driven by artificial intelligence. Technology in Society, vol. 60, February, pp. 1-11, art. n. 101198, https://doi.org/10.1016/j.techsoc.2019.101198

Coccia M. 2021. The impact of first and second wave of the COVID-19 pandemic: comparative analysis to support control measures to cope with negative effects of future infectious diseases in society. Environmental Research, vol. 197, June, Article number 111099, https://doi.org/10.1016/j.envres.2021.111099

Coccia M. 2021a. Pandemic Prevention: Lessons from COVID-19. Encyclopedia 2021, 1, 433-444. MDPI, Basel, Switzerland, Encyclopedia of COVID-19, open access journal, https://doi.org/10.3390/encyclopedia1020036

Coccia M. 2021b. The effects of atmospheric stability with low wind speed and of air pollution on the accelerated transmission dynamics of COVID-19. International Journal of Environmental Studies, vol. 78, n. 1, pp. 1-27, https://doi.org/10.1080/00207233.2020.1802937

Coccia M. 2021c. Effects of the spread of COVID-19 on public health of polluted cities: results of the first wave for explaining the dejà vu in the second wave of COVID-19 pandemic and epidemics of future vital agents. Environmental Science and Pollution Research. 28(15), 19147-19154. https://doi.org/10.1007/s11356-020$11662-7$

Coccia M. 2021d. The relation between length of lockdown, numbers of infected people and deaths of Covid-19, and economic growth of countries: Lessons learned to cope with future pandemics similar to Covid-19. Science of The Total Environment, n. 145801. https://doi.org/10.1016/j.scitotenv.2021.145801

Coccia M. 2021e. High health expenditures and low exposure of population to air pollution as critical factors that can reduce fatality rate in COVID-19 pandemic crisis: a global analysis Environmental Research, vol. 199, Article number 111339, https://doi.org/10.1016/j.envres.2021.111339

Coccia M. 2021f. Comparative Critical Decisions in Management. In: Farazmand A. (eds), Global Encyclopedia of Public Administration, Public Policy, and Governance. Springer Nature Switzerland AG 2020, Springer, Cham. https://doi.org/10.1007/978-3-319-31816-5_3969-1

Coccia M. 2021g. How a Good Governance of Institutions Can Reduce Poverty and Inequality in Society? In Nezameddin Faghih, Ali Hussein Samadi (Editor) Legal-Economic Institutions, Entrepreneurship, and Management, Perspectives on the Dynamics of Institutional Change from Emerging Markets, Springer Nature Switzerland AG, DOI 978-3-030-60978-8_4, https://doi.org/10.1007/978-3-030-60978-8, pp. 65-94 
Coccia M. 2021h. How do low wind speeds and high levels of air pollution support the spread of COVID-19? Atmospheric Pollution Research, vol. 12, n.1, pp. 437-445., https://doi.org/10.1016/j.apr.2020.10.002.

Coccia M. 2022. Preparedness of countries to face covid-19 pandemic crisis: Strategic positioning and underlying structural factors to support strategies of prevention of pandemic threats, Environmental Research, Volume 203, n. 111678, ISSN 0013-9351, https://doi.org/10.1016/j.envres.2021.111678.

Coccia M., Bellitto M. 2018. Human progress and its socioeconomic effects in society, Journal of Economic and Social Thought, vol. 5, n. 2, pp. 160-178, http://dx.doi.org/10.1453/jest.v5i2.1649

Coccia M., Benati I. 2018. Rewards in public administration: A proposed classification, Journal of Social and Administrative Sciences, vol. 5, n. 2, pp. 68-80, http://dx.doi.org/10.1453/jsas.v5i2.1648.

Coccia M., Cadario E. 2014. Organisational (un)learning of public research labs in turbulent context. International Journal of Innovation and Learning, vol. 15, n. 2, pp.115-129, https://doi.org/10.1504/IJIL.2014.059756

Coccia M., Finardi U. 2012. Emerging nanotechnological research for future pathway of biomedicine. International Journal of Biomedical nanoscience and nanotechnology, vol. 2, nos. 3-4, pp. 299-317. DOI: 10.1504/IJBNN.2012.051223

Coccia M., Finardi U. 2013. New technological trajectories of non-thermal plasma technology in medicine. Int. J. Biomedical Engineering and Technology, vol. 11, n. 4, pp. 337-356, DOI: 10.1504/IJBET.2013.055665

Coccia M., Rolfo S. 2010. New entrepreneurial behaviour of public research organizations: opportunities and threats of technological services supply. International Journal of Services Technology and Management, vol. 13, n. 1/2, pp. 134-151. https://doi.org/10.1504/IJSTM.2010.029674

Coccia M., Wang L. 2015. Path-breaking directions of nanotechnology-based chemotherapy and molecular cancer therapy, Technological Forecasting \& Social Change, 94(May):155-169.

https://doi.org/10.1016/j.techfore.2014.09.007

Coccia M., Wang L. 2016. Evolution and convergence of the patterns of international scientific collaboration, Proceedings of the National Academy of Sciences of the United States of America, February 23, vol. 113, n. 8, pp. 2057-2061, .

Coccia M., Watts J. 2020. A theory of the evolution of technology: technological parasitism and the implications for innovation management, Journal of Engineering and Technology Management, vol. 55, https://doi.org/10.1016/j.jengtecman.2019.11.003

Cylus J., Pantel, D., van Ginneken E. 2021. Who should be vaccinated first? Comparing vaccine prioritization strategies in Israel and European countries using the Covid-19 Health System Response Monitor. Israel journal of health policy research, 10(1), 16. https://doi.org/10.1186

Danon, L., Brooks-Pollock, E., Bailey, M., Keeling, M. 2021. A spatial model of COVID-19 transmission in England and Wales: Early spread, peak timing and the impact of seasonality, Philosophical Transactions of the Royal 
Society B: Biological Sciences, 376(1829),20200272

Dbouk, T., Drikakis, D. 2020. Weather impact on airborne coronavirus survival. Physics of Fluids, 32 (9), art. no. 093312. doi: $10.1063 / 5.0024272$

Dbouk, T., Drikakis, D. 2021. Fluid dynamics and epidemiology: Seasonality and transmission dynamics, Physics of Fluids 33(2),021901

de Vlas, S. J., Coffeng, L. E. 2021. Achieving herd immunity against COVID-19 at the country level by the exit strategy of a phased lift of control. Scientific reports, 11(1), 4445. https://doi.org/10.1038/s41598-021-83492-7

Engelbrecht, F. A., Scholes, R. J. 2021. Test for Covid-19 seasonality and the risk of second waves. One health (Amsterdam, Netherlands), 12, 100202. https://doi.org/10.1016/j.onehlt.2020.100202

Faes C., Abrams S., Van Beckhoven D., Meyfroidt G., Vlieghe E., Hens N., Belgian Collaborative Group on COVID19 Hospital Surveillance. 2020. Time between Symptom Onset, Hospitalisation and Recovery or Death:

Statistical Analysis of Belgian COVID-19 Patients. Int. J. Environ. Res. Public Health, 17, 7560.

Feng, J., LI, Q. 2021. How to ensure vaccine safety: An evaluation of China's vaccine regulation system, Vaccine 39(37), pp. 5285-5294

Fontanet A., Cauchemez, S. 2020. COVID-19 herd immunity: where are we? Nature reviews. Immunology, 20(10), 583-584. https://doi.org/10.1038/s41577-020-00451-5

GAVI 2021. THE FOUR MAIN TYPES OF COVID-19 VACCINE. https://www.gavi.org/vaccineswork/there-are-fourtypes-covid-19-vaccines-heres-how-they-work (accessed 6 September 2021).

Gozzi, N., Bajardi, P., Perra, N. 2021. The importance of non-pharmaceutical interventions during the COVID-19 vaccine rollout, PLoS Computational Biology 17(9),e1009346

Heaton P. M. 2020. The Covid-19 Vaccine-Development Multiverse. The New England journal of medicine, 383(20), 1986-1988. https://doi.org/10.1056/NEJMe2025111

Hoogeveen, M.J., Hoogeveen, E.K. 2021. Comparable seasonal pattern for COVID-19 and flu-like illnesses, One Health 13,100277

lanevski, A., Zusinaite, E., Shtaida, N., Kallio-Kokko, H., Valkonen, M., Kantele, A., Telling, K., Lutsar, I., Letjuka, P., Metelitsa, N., Oksenych, V., Dumpis, U., Vitkauskiene, A., Stašaitis, K., Öhrmalm, C., Bondeson, K., Bergqvist, A., Cox, R. J., Tenson, T., Merits, A., ... Kainov, D. E. 2019. Low Temperature and Low UV Indexes Correlated with Peaks of Influenza Virus Activity in Northern Europe during 2010-2018. Viruses, 11(3), 207. https://doi.org/10.3390/v11030207

loannidis, J.P.A. 2021. Benefit of COVID-19 vaccination accounting for potential risk compensation, npj Vaccines 6(1),99

Islam, N., Bukhari, Q., Jameel, Y., Shabnam, S., Erzurumluoglu, A.M., Siddique, M.A., Massaro, J.M., (... D'Agostino, R.B. 2021. COVID-19 and climatic factors: A global analysis, (2021) Environmental Research, 193, 
art. no. 110355. doi: 10.1016/j.envres.2020.110355

Jalkanen, P., Kolehmainen, P., Häkkinen, H.K., (... Kantele, A., Julkunen, I. 2021. COVID-19 mRNA vaccine induced antibody responses against three SARS-CoV-2 variants, Nature Communications 12(1),3991

Jeyanathan M, Afkhami S, Smaill F, Miller MS, Lichty BD, Xing Z. 2020. Immunological considerations for COVID-19 vaccine strategies. Nat Rev Immunol. 20(10):615-632. doi: 10.1038/s41577-020-00434-6.

Johns Hopkins Center for System Science and Engineering, 2021. Coronavirus COVID-19 Global Cases, https://gisanddata.maps.arcgis.com/apps/opsdashboard/index.html\#/bda7594740fd40299423467b48e9ecf6 (accessed in 4 January 2021).

Karapiperis, C., Kouklis, P., Papastratos, S., (... Angelis, L., Ouzounis, C.A. 2021. A strong seasonality pattern for covid-19 incidence rates modulated by UV radiation levels. Viruses 13(4),574

Kerr, G.H., Badr, H.S., Gardner, L.M., Perez-Saez, J., Zaitchik, B.F. 2021. Associations between meteorology and COVID-19 in early studies: Inconsistencies, uncertainties, and recommendations, One Health12,100225

Kronfeld-Schor, N., Stevenson, T. J., Nickbakhsh, S., Schernhammer, E. S., Dopico, X. C., Dayan, T., Martinez, M., \& Helm, B. (2021). Drivers of Infectious Disease Seasonality: Potential Implications for COVID-19. Journal of biological rhythms, 36(1), 35-54. https://doi.org/10.1177/0748730420987322

Kumar, M., Mazumder, P., Mohapatra, S., (... Sonne, C., Kuroda, K. 2021. A chronicle of SARS-CoV-2: Seasonality, environmental fate, transport, inactivation, and antiviral drug resistance, Journal of Hazardous Materials 405,124043

Lab24 2021. Vaccino, I dati per paese | II Sole 24 ORE. https://lab24.ilsole24ore.com/coronavirus/ (accessed 20th June 2021)

LabCorp 2020. Individuals/ Patients, Getting COVID-19 Test Results-How to Get My COVID-19 Test Result. https://www.labcorp.com/coronavirus-disease-covid-19/individuals/test-results (accessed in October 2020)

Liu, X., Huang, J., Li, C., Zhao, Y., Wang, D., Huang, Z., \& Yang, K. 2021. The role of seasonality in the spread of COVID-19 pandemic. Environmental research, 195, 110874. https://doi.org/10.1016/j.envres.2021.110874

Maharaj A. S., Parker, J., Hopkins, J. P., Gournis, E., Bogoch, I. I., Rader, B., Astley, C. M., Ivers, N., Hawkins, J. B., VanStone, N., Tuite, A. R., Fisman, D. N., Brownstein, J. S., \& Lapointe-Shaw, L. 2021. The effect of seasonal respiratory virus transmission on syndromic surveillance for COVID-19 in Ontario, Canada. The Lancet. Infectious diseases, 21(5), 593-594. https://doi.org/10.1016/S1473-3099(21)00151-1

Mathieu, E., Ritchie, H., Ortiz-Ospina, E. et al. 2021. A global database of COVID-19 vaccinations. Nat Hum Behav 5, 947-953 (2021). https://doi.org/10.1038/s41562-021-01122-8

MAYO CLINIC 2021. Different types of COVID-19 vaccines: How they work. https://www.mayoclinic.org/diseases-conditions/coronavirus/in-depth/different-types-of-covid-19-vaccines/art20506465 (accessed 6 September 2021). 
Ministero della Salute 2021. COVID-19 - Situazione in Italia.

http://www.salute.gov.it/portale/nuovocoronavirus/dettaglioContenutiNuovoCoronavirus.jsp?

lingua=italiano\&id=5351\&area=nuovoCoronavirus\&menu=vuoto (Accessed June 2021)

Moriyama, M.; Hugentobler, W.J.; Iwasaki, A. Seasonality of Respiratory Viral Infections. Annu. Rev. Virol. 2020, 7, 83-101.

Our World in Data 2021. Statistics and Research, Coronavirus (COVID-19) Vaccinations.

https://ourworldindata.org/covid-vaccinations (Accessed 20 September 2021).

Pawelec G., McElhaney, J. 2021. Unanticipated efficacy of SARS-CoV-2 vaccination in older adults, Immunity and Ageing 18(1),7

Prieto Curiel R., González Ramírez, H. 2021. Vaccination strategies against COVID-19 and the diffusion of antivaccination views, Scientific Reports 11(1),6626

Randolph H. E., Barreiro L. B. 2020. Herd immunity: understanding COVID-19. Immunity 52, 737-741

Redwan E. M. 2021. COVID-19 pandemic and vaccination build herd immunity. European review for medical and pharmacological sciences, 25(2), 577-579. https://doi.org/10.26355/eurrev_202101_24613

Rosario, D.K.A., Mutz, Y.S., Bernardes, P.C., Conte-Junior, C.A. 2020. Relationship between COVID-19 and weather: Case study in a tropical country, (2020) International Journal of Hygiene and Environmental Health, 229, art. no. 113587. doi: 10.1016/j.ijheh.2020.113587

Rosen, B., Waitzberg, R., Israeli, A.2021. Israel's rapid rollout of vaccinations for COVID-19, Israel Journal of Health Policy Research10(1),6

Rosenberg E.S., Holtgrave D.R., Dorabawila V., et al. 2021. New COVID-19 Cases and Hospitalizations Among Adults, by Vaccination Status - New York, May 3-July 25, 2021. MMWR Morb Mortal Wkly Rep 2021;70:11501155. DOI: http://dx.doi.org/10.15585/mmwr.mm7034e1external icon.

Roussel, M., Pontier, D., Cohen, J.-M., Lina, B., Fouchet, D. 2016. Quantifying the role of weather on seasonal influenza (2016) BMC Public Health, 16 (1), art. no. 441. doi: 10.1186/s12889-016-3114-x

Runkle, J. D., Sugg, M. M., Leeper, R. D., Rao, Y., Matthews, J. L., \& Rennie, J. J. 2020. Short-term effects of specific humidity and temperature on COVID-19 morbidity in select US cities. The Science of the total environment, 740, 140093. https://doi.org/10.1016/j.scitotenv.2020.140093

Şahin M. 2020. Impact of weather on COVID-19 pandemic in Turkey. Science of the Total Environment, 728, art. no. 138810. doi: 10.1016/j.scitotenv.2020.138810

Sarmadi M., Nilufar Marufi, Vahid Kazemi Moghaddam 2020. Association of COVID-19 global distribution and environmental and demographic factors: An updated three-month study. Environmental Research 188, 109748.

Shaman, J.; Galanti, M. 2020. Will SARS-CoV-2 become endemic? Science, 370, 527-529. 
Smit A. J., Fitchett J. M., Engelbrecht F. A., Scholes R. J., Dzhivhuho G., Sweijd N. A. 2020. Winter Is Coming: A Southern Hemisphere Perspective of the Environmental Drivers of SARS-CoV-2 and the Potential Seasonality of COVID-19. International journal of environmental research and public health, 17(16), 5634.

https://doi.org/10.3390/ijerph17165634

Takagi, H., Kuno, T., Yokoyama, Y., Ueyama, H., Matsushiro, T., Hari, Y., Ando, T. 2020. The higher temperature and ultraviolet, the lower COVID-19 prevalence-meta-regression of data from large US cities, (2020) American Journal of Infection Control, 48 (10), pp. 1281-1285. doi: 10.1016/j.ajic.2020.06.181

Tran, T.N.-A., Wikle, N.B., Albert, E., (... Hanks, E.M., Boni, M.F. 2021. Optimal SARS-CoV-2 vaccine allocation using real-time attack-rate estimates in Rhode Island and Massachusetts, BMC Medicine19(1),162

Yoshikawa T. 2021. Implementing vaccination policies based upon scientific evidence in Japan, Vaccine 39(38), pp. 5447-5450

Zhang B, Zhou X, Qiu Y, Song Y, Feng F, Feng J, et al. 2020. Clinical characteristics of 82 cases of death from COVID-19. PLoS ONE 15(7): e0235458. https://doi.org/10.1371/journal.pone.0235458

Zhong J., Zhang X., Dong Y., Wang Y., Wang J., Zhang Y., et al., 2018. Feedback effects of boundary-layer meteorological factors on explosive growth of PM2.5 during winter heavy pollution episodes in Beijing from 2013 to 2016. Atmos. Chem. Phys. 18, $247 e 258$.

Zoran, M.A., Savastru, R.S., Savastru, D.M., (... Baschir, L.A., Tenciu, D.V. 2021. Exploring the linkage between seasonality of environmental factors and COVID-19 waves in Madrid, Spain, Process Safety and Environmental Protection, 152, pp. 583-600

\section{Figures}

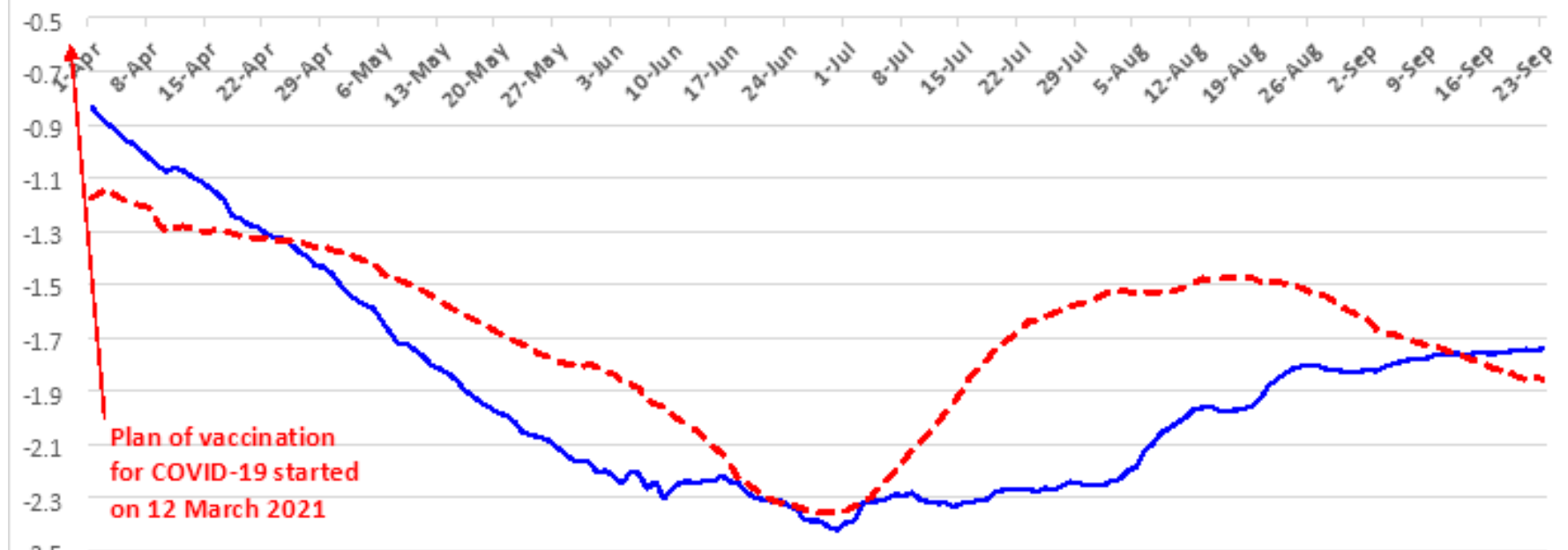

$-2.5$

\section{Figure 1}


Trends of confirmed cases normalized from April to September in 2020 and 2021, Italy Note: log scale on y-axis for better visualization of MM7 values

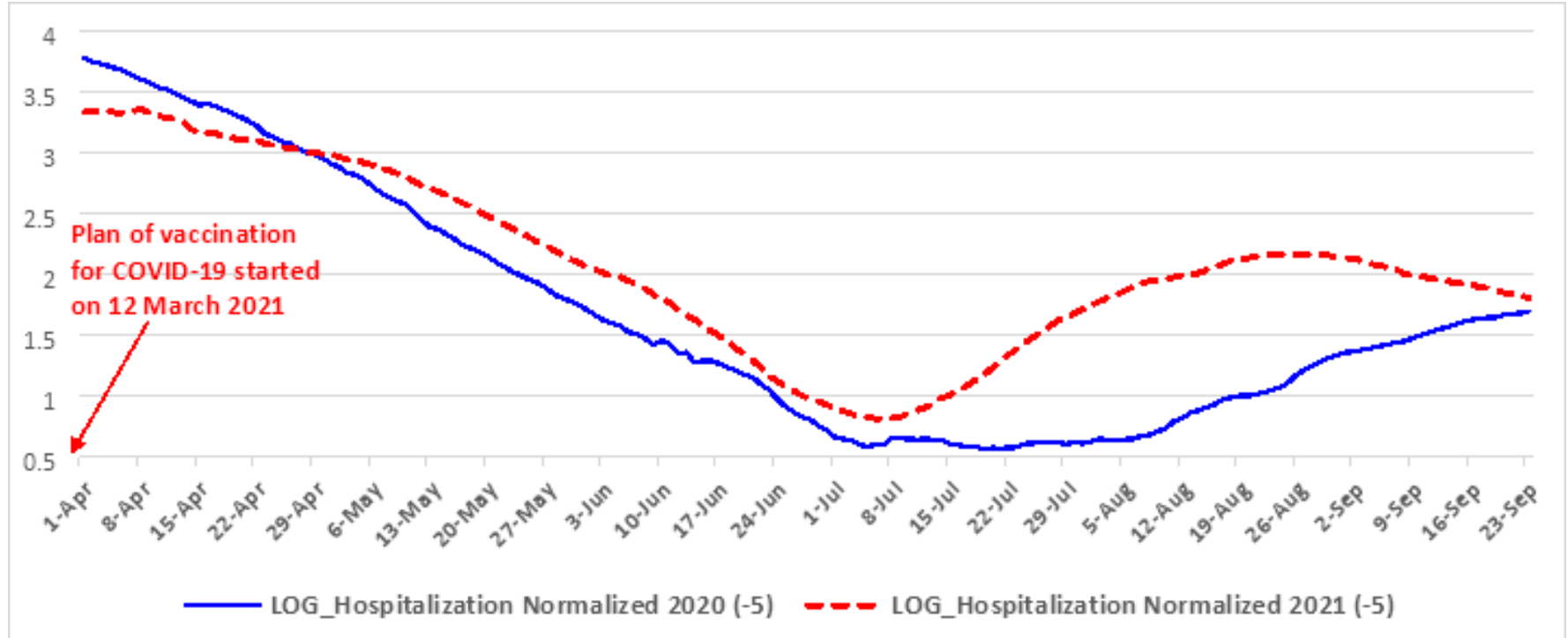

Figure 2

Trends of hospitalized people normalized from April to September in 2020 and 2021, Italy Note: log scale on yaxis for better visualization of MM7 values

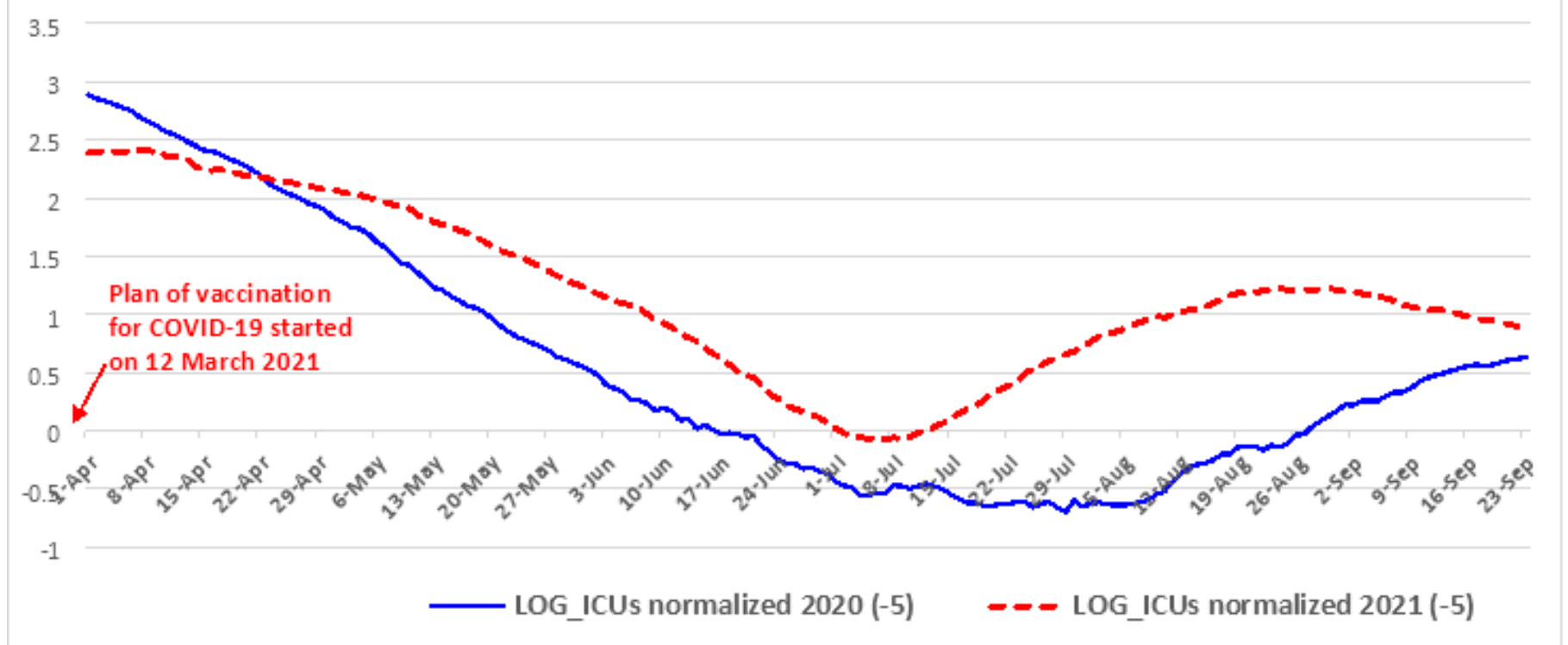

Figure 3

Trends of ICUs normalized from April to September in 2020 and 2021, Italy Note: log scale on y-axis for better visualization of MM7 values 


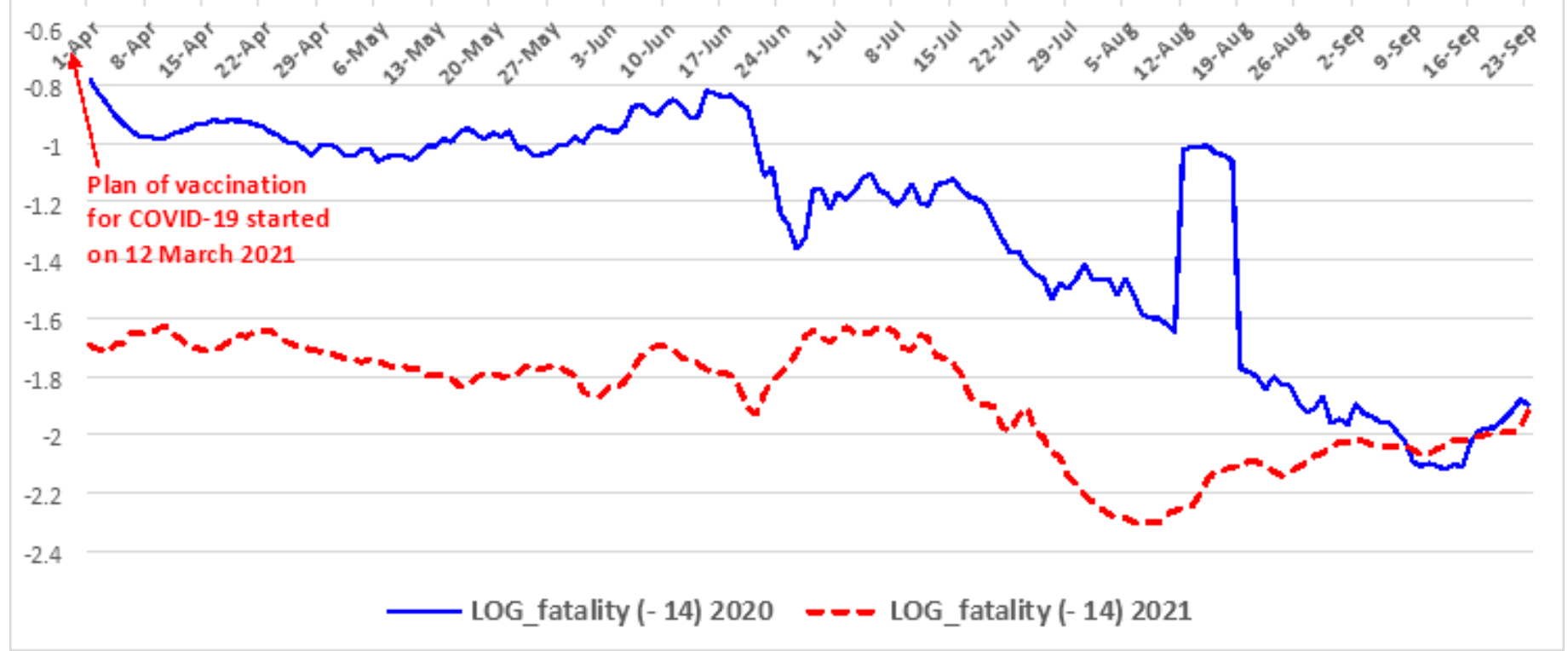

Figure 4

Trends of fatality rate from April to September in 2020 and 2021, Italy Note: log scale on y-axis for better visualization of MM7 values 